\title{
EL ECO-ETNODESARROLLO EL CHOCÓ BIOGEOGRÁFICO. ESTUDIO A PARTIR DEL EXTRACTIVISMO Y LAS LUCHAS SOCIALES POR EL TERRITORIO*
}

\author{
THE ECO-ETHNO-DEVELOPMENT IN THE CHOCÓ \\ BIOGEOGRAPHIC: STUDY FROM THE EXTRACTIVISM AND THE \\ SOCIAL STRUGGLES FOR THE TERRITORY
}

\author{
YenNesit PALACIOS VALENCIA** \\ ÁNGELA CECILIA GONZÁLEZ*** \\ Diego MONSALVE BUILES $* * * *$
}

Recibido: 20 de agosto de 2017 - Aceptado: 20 de septiembre de 2017 - Publicado 31 julio de 2018 DOI: $10.24142 /$ raju.v13n26a4

\footnotetext{
* El presente artículo es producto del proyecto de investigación "Estudio del fenómeno del desplazamiento forzado por el conflicto armado en Colombia, a partir de su impacto en la población afrodescendiente e indígena del departamento del Chocó".

** PhD en Derechos Humanos y Desarrollo de la Universidad Pablo de Olavide (UPO); PhD en Derecho, Gobierno y Políticas Públicas de la Universidad Autónoma de Madrid; Magíster en Derecho Constitucional del Centro de Estudios Políticos y Constitucionales de Madrid, en asociación con la Universidad Internacional Menéndez Pelayo; Magíster en Derechos Humanos, Interculturalidad y Desarrollo de la UPO; Magíster en Relaciones Internacionales de la Universidad Internacional de Andalucía; Especialista en Cultura Política y Derechos Humanos de la Universidad Autónoma Latinoamericana de Medellín; Abogada de la Universidad de San Buenaventura, Seccional Medellín. Correo electrónico: yennesit.palaciosva@unaula.edu.co

*** Estudiante Maestría en Educación y Derechos Humanos de la Universidad Autónoma Latinoamericana de Medellín; Especialista en Derecho de Familia de la Universidad Autónoma Latinoamericana de Medellín; Abogada de la Universidad de Medellín. Correo electrónico: acgs23@yahoo

**** Estudiante Maestría en Educación y Derechos Humanos de la Universidad Autónoma Latinoamericana de Medellín; Filósofo de la Universidad de Antioquia; Abogado de la Universidad de Medellín. Correo electrónico: damonsalveb@escolme.edu.co
} 


\section{Resumen}

El objetivo del presente artículo es demostrar, desde la visión del eco-etnodesarrollo, la crisis humanitaria que padece el departamento del Chocó, teniendo en cuenta la grave afectación de los diversos grupos étnicos en sus territorios por causa del desplazamiento forzado por el conflicto armado, el riesgo en la extinción de poblaciones indígenas y tribales, las prácticas de recursos extractivos, que han puesto a los territorios en situaciones de disputa, y el narcotráfico, que evidencian la degradación que padece el departamento, ligado a los márgenes de pobreza que enfrenta, aún con la enorme riqueza ambiental y étnica que posee.

Palabras claves: Chocó, conflicto armado, extractivismo, grupos étnicos, territorio, eco-etnodesarrollo.

\section{Abstract}

The objective of the article is to demonstrate, from the perspective of eco-ethno-development, the humanitarian crisis that the department of Chocó has been suffering, considering the serious affectation of diverse ethnic groups in their territories: forced displacement due to the armed conflict, the risk in the extinction of indigenous and tribal populations, practices of extracting resources, which have put the territories in situations of dispute, and the drug trafficking evidence the degradation suffered by the Department of Choco, linked to the margins of poverty that it faces, even with the enormous environmental and ethnic wealth that it possesses.

Keywords: Chocó, armed conflict, extractivism, ethnic groups, territory, eco-ethnodevelopment. 
El eco-etnodesarrollo en el Chocó biogeográfico.

Estudio a partir del extractivismo y las luchas sociales por el territorio

\section{INTRODUCCIÓN}

En la actualidad, la lucha por la defensa del territorio constituye uno de los pilares fundamentales de los movimientos sociales en Colombia, pues aunque en ellos se materializa la propia existencia, a través de diversas acciones del hacer humano, el conflicto armado ha imposibilitado el desarrollo progresivo de los derechos económicos, sociales y culturales, generando desterritorialización, despojo de la tierra y desplazamiento forzado, por mencionar solamente algunos aspectos. Por ello, debe precisarse, como punto de partida, que el análisis sobre el territorio es indispensable para la comprensión de la estructuración actual de la formación socio-espacial colombiana, reflexión que se hace desde años atrás para visualizar nuestra producción de futuro (Montañez y Delgado, 1998).

Partiendo de dicho contexto, esto es, desplazamiento forzado, desterritorialización y violaciones de derechos humanos, como factor que ha impactado los territorios de las poblaciones afrodescendientes, indígenas y tribales, este escrito se estructura en cinco partes: en la primera se pone en contexto cómo el desplazamiento forzado por el conflicto armado, ligado a otras prácticas como el extractivismo minero y forestal, ha afectado el acervo cultural de los grupos étnicos, ubicando a los territorios en situaciones de disputa; la segunda hace una caracterización del Chocó como un departamento inmerso en la pobreza en medio de la riqueza; luego se explica el reconocimiento constitucional de las comunidades étnicas a través de la Constitución de 1991, al tiempo que se advierte la realidad de los grupos étnicos invocando la importancia de las luchas sociales por el territorio ante el abandono estatal. Posteriormente, se hace una aproximación epistemológica al concepto de territorio, y se finaliza con la relación entre eco-etnodesarrollo, despojo y extractivismo, teniendo en cuenta las afectaciones y direcciones que han padecido numerosos grupos étnicos en Colombia por la participación de distintos protagonistas en el conflicto armado: los grupos guerrilleros, las fuerzas del Estado, los paramilitares y las bandas criminales emergentes. Actores que, junto con el fenómeno del narcotráfico, han influido directamente en la situación jurídica, política, económica y social del país, dejando toda clase de estragos y víctimas a su paso; entre ellas sobresalen las poblaciones afrodescendientes, indígenas y tribales. Estos colectivos han sido afectados de manera especial en la relación intrínseca con su territorio, con prácticas extractivas que destruyen el acervo cultural y la riqueza biogeográfica. Por lo tanto, los derechos que se apelan trascienden una cuestión de supervivencia desde la cosmovisión del eco-etnodesarrollo. 


\section{CONTEXTO}

En el contexto del conflicto armado Colombia se ha convertido en una nación desplazada; fenómeno que ha generado una estrecha y compleja relación entre etnicidad, despojo, desplazamiento y desterritorialización, dando lugar a procesos de resistencia, por medio de una apuesta política emancipadora, para la recuperación de territorios colectivos, procesos que exigen, de manera constante, la reivindicación de los derechos humanos en la defensa por los territorios.

La verdad es que el problema del conflicto armado - con independencia de los Acuerdos de Paz, de La Habana, Cuba— ha traído aparejadas consecuencias desafortunadas que afectan el desarrollo cultural y medioambiental de los territorios colectivos, propios de las culturas afrodescendientes, indígenas y tribales. Situación que, años atrás, quedara evidenciada en los resultados del Proyecto Biopacífico (1998a, 1998b, 1999), el cual alertó que la diversidad biológica de la región estaba seriamente amenazada y sus culturas en peligro. De lo anterior, se desprende la necesidad de políticas ambientales que sean diseñadas e implementadas desde lógicas diferentes, primando el reconocimiento de los derechos de las poblaciones locales y de la naturaleza en sí misma, antes que la racionalidad económica en beneficio de un sector dominante (Roa y Navas, 2014).

En este contexto, la hipótesis que se plantea es que el desplazamiento forzado por el conflicto armado, ligado a otras dinámicas como el narcotráfico, el extractivismo minero y forestal, ha afectado a los grupos étnicos, ubicando a los territorios en situaciones de disputa. Sobre el particular, el desplazamiento forzado, en sus distintas modalidades y manifestaciones, es una forma de violencia que tiene una historia antigua y compleja en el conflicto colombiano:

En el contexto de la violencia contemporánea en Colombia más de seis millones de personas se han visto forzadas a desplazarse dentro y fuera del territorio nacional, abandonando sus hogares, sus tierras y territorios, sus bienes, sus costumbres, sus comunidades y sus formas de vida. Para quienes se han visto forzados a desplazarse dentro del país, se han encontrado con una política pública insuficiente y, en muchas ocasiones, inexistente (Centro Nacional de Memoria Histórica, 2015, p. 40). 
Este fenómeno, descrito por diversos investigadores como colonización armada, ha decantado modelos institucionales alternos, formas de control social permeadas o medidas por el poder armado; al mismo tiempo que se configuran espacios marginales a la acción estatal. De estos procesos han participado la mayoría de los pueblos indígenas, los cuales han experimentado la guerra dentro de su propia cotidianidad, en la medida en que la intensificación del conflicto transforma sus territorios en el espacio donde diferentes actores pulsan por ejercer control (Villa y Houghton, 2004, p. 15).

Si bien, Colombia es un país multiétnico, pluricultural y multilingüe, consagración emanada del propio texto constitucional, los antecedentes del conflicto armado evidencian que el nivel de afectación de algunos grupos étnicos, afrodescendientes, indígenas y tribales es desbordante, pues la regresividad de los derechos económicos, sociales y culturales sigue siendo una constante ante el actuar inoperante del Estado (crf. Amnistía Internacional, 2010, 2016; CIDH, 2015a; Corporación Humanas Colombia, 2015; García, 2004; Escobar, 2004; Villa y Houghton, 2004 y UNICEF, 2003).

Idea que se pone en boga con las negociaciones de paz, desde el año 2012 , teniendo en cuenta que la crisis humanitaria que ha vivido el país, y en particular el departamento del Chocó, deja un balance crítico que refleja masacres, desapariciones y desplazamientos forzados, riesgos en la extinción de poblaciones indígenas y tribales, dada la apropiación de sus territorios ancestrales por parte de grupos armados para la explotación de recursos extractivos y narcotráfico que son, en suma, prácticas reiteradas que evidencian la degradación y que lleva a la pobreza a muchas zonas del país, entre ellas, se insiste, el departamento del Chocó.

\section{CARACTERIZACIÓN: EL CHOCÓ INMERSO EN LA POBREZA EN MEDIO DE LA RIQUEZA}

El Pacífico colombiano, integrado por los departamentos del Valle del Cauca, Chocó, Cauca y Nariño, es una región ancestral de grupos étnicos que ha sufrido forzosamente los impactos del conflicto armado; también posee una elevada concentración de pobreza, la cual, en el departamento del Chocó, por ejemplo, es significativa. Lo paradójico es, en el caso del Chocó, que se trata de un departamento con una enorme riqueza en fauna, flora y cultura. Según estudios, en el Pacífico se concentra cerca del $10 \%$ de la biodiversidad del planeta, con importantes niveles de conservación biótica 
que aún se mantienen en diversas franjas de este territorio (Defensoría del Pueblo, 2016).

En la región del Pacífico colombiano —ubicada en el Pacífico nortees donde más abunda el agua, debido a su posición geográfica (Lobo-Guerrero, 1993). Sus características biogeográficas, climáticas, culturales, políticas y económicas la convierten en una región diferenciada del conjunto de la sociedad colombiana. No obstante, ha estado vinculada, históricamente, con el resto del país a través de una economía extractiva basada en su oferta natural y ambiental, que la convierten en un territorio de despensa (Proyecto Biopacífico, 1998b, pp. 15-16).

En el caso de la flora, en el Chocó se han registrado 3.500 especies, pero su número podría superar las 10.000 , lo cual equivale al $20 \%$ de las existentes en Colombia (Casas, 1994), de ahí que se le llamé también Chocó biogeográfico, pues posee uno de los más altos niveles de diversidad en el mundo, incluida una alta presencia de especies endémicas, resaltando su riqueza hidrográfica, ecológica, forestal y minera. A su vez, es el único departamento con costas en los océanos Pacífico y Atlántico, circunstancia que lo sitúa en una posición geográfica estratégica en diferentes aspectos, algunos de ellos asociados a la proliferación de grupos armados, dada su condición selvática con difícil acceso, sin demeritar su clima tropical-húmedo, caracterizado por las altas temperaturas durante todo el año, siendo una de las zonas con mayor promedio de lluvias, incluso a nivel mundial.

Realmente, lo que más ha movido la economía ha sido el auge del oro, la plata, el platino y el cobre, sin dejar de lado la riqueza maderera, que ha sido también fuente de uso, abuso y explotación. A nivel de educación, aunque el magisterio es una de las profesiones más representativas, su población cuenta con altos índices de analfabetismo y el desarrollo industrial, a diferencia de otros departamentos, como Antioquia, es prácticamente inexistente.

Por otra parte, si bien resalta como característica significativa del departamento del Chocó el auge del proceso de mestizaje, durante y después de la época de la conquista, en la actualidad es un territorio conformado, principalmente, por afrocolombianos e indígenas. De hecho, el censo elaborado por el Departamento Administrativo Nacional de Estadística (2005), demuestra que en el territorio se encuentran asentadas las etnias emberá, emberá chamí, emberá katío, tule, waunan; mientras que el 82,12\% de la población es afrocolombiana.

En general, las comunidades que habitan el territorio tienen una estrecha relación con la naturaleza, los ríos y el mar; son lugares de encuentro, 
de paso y de salida, no solo conectan al territorio, sino que permiten la producción y comercialización de la pesca, siendo un aporte importante en la dieta básica de sus comunidades. Si bien, los ríos cumplen un papel fundamental uniendo al departamento del Chocó, como eje transversal de la vida en comunidad, también es cierto que es un territorio que goza de un elevado abandono gubernamental, lo cual se agrava con el nivel de corrupción política a nivel departamental; esto hace que se posicione en las primeras filas entre las regiones con peor índice de pobreza en el país.

Los ríos que en el Pacífico corren paralelos, en el encuentro de las organizaciones se juntan, la oralidad rasgo propio a la cultura del negro se exacerba y de modo reiterativo se cuentan las historias de los ríos. De grandes dragas que a su paso todo lo destruyeron, de franceses y norteamericanos que impusieron su ley para extraer todo el oro, de aserríos y grandes empresas que acabaron los bosques y de retroexcavadoras que dejan sin trabajo al pequeño minero. La historia ignominiosa de la extracción de los recursos del Pacífico es tejida en el encuentro, los del norte conocen que su experiencia no es diferente de los del sur, en ese momento se forja la identidad en las penurias del pasado y en la certeza de un destino común. Es allí donde un concepto de región aparece manifiesto y aprendido de forma vivencial (Villa, 1998).

El Chocó, cuya capital es la ciudad de Quibdó, pese a tener una posición geográfica estratégica, siendo además el único departamento que limita con Panamá — como se puede ver en la figura 4.1—, tiene diferentes ríos que lo bordean, como el Atrato, pero se encuentra aislado del resto del país pues su sistema de transporte es realmente precario, esto lo obliga, para comunicarse con otras regiones, al uso de la vía área. Las carreteras del departamento, a la fecha, son lamentables y no existen vías que comuniquen a los municipios entre sí; tampoco cuenta con una vía al mar. En el Chocó lo que parece ser una gran ventaja se solapa e impacta en detrimento de sus pobladores, teniendo en cuenta que, además de los márgenes de pobreza:

Los modelos de desarrollo imperante lo han venido convirtiendo en una zona de extracción y exportación de productos naturales - biológicos y mineros- con poco beneficio para la región y sus comunidades locales. (...) Son evidentes los impactos negativos e irreversibles sobre los hábitats naturales, con graves consecuencias para la diversidad biológica, la integridad y la permanencia de las culturas 
tradicionales e, incluso, para las condiciones regionales y globales (Casas, 1994, p. 153).

Bonet (2009), en su texto ¿Por qué es pobre el Chocó? lo explica de la siguiente manera: durante el periodo de auge, ocurrido en las primeras décadas del siglo Xx, en el cual la economía chocoana mantenía una vocación exportadora, el comercio por el río Atrato brindó una ventaja comparativa importante. A medida que la economía colombiana se cerraba, después de la Segunda Guerra Mundial, Chocó perdió parte de su ventaja natural y, por el contrario, se vio geográficamente asilada de las zonas dinámicas del interior del país.

Vale anotar que, desde tiempos de la Conquista, durante la Colonia y luego de la instauración de la República,

las clases dirigentes concibieron la Región Pacífica como una fuente inagotable de recursos. Conforme a esto instauraron proyectos y economías de enclave. Los puertos naturales de la región se constituyeron a través del tiempo en puntos de escala mercantil para el comercio internacional, lo que significó el desarrollo e implantación de infraestructuras al margen de las necesidades o demandas de la población local (Defensoría del Pueblo de Colombia, 2016).

Son diversas las razones, además de los factores expresados, que pueden explicar la situación de pobreza que vive el Chocó: Galvis, Moyano y Alba (2016) se basan en los escritos de Angus Deaton (Premio Nobel de Economía), con su libro El gran escape, para intentar explicar por qué es pobre Chocó. Los autores argumentan, bajo la tesis de Deaton:

que el Estado y la sociedad civil deben suscribir un contrato, mediante el cual el primero pueda garantizar los recursos para llevar a cabo funciones como preservar la integridad del territorio y mantener el monopolio de la violencia; y el segundo, pueda tener acceso a la seguridad y otros bienes públicos para su bienestar (p. 4).

Para que ese contrato tenga lugar, insisten los autores, las instituciones del Estado deben ser reconocidas por su transparencia y eficiencia. En cuyo caso, las instituciones legales y políticas juegan un papel fundamental en la configuración del ambiente que puede alimentar la prosperidad y el desarrollo económico (Galvis, Moyano y Alba, 2016). 


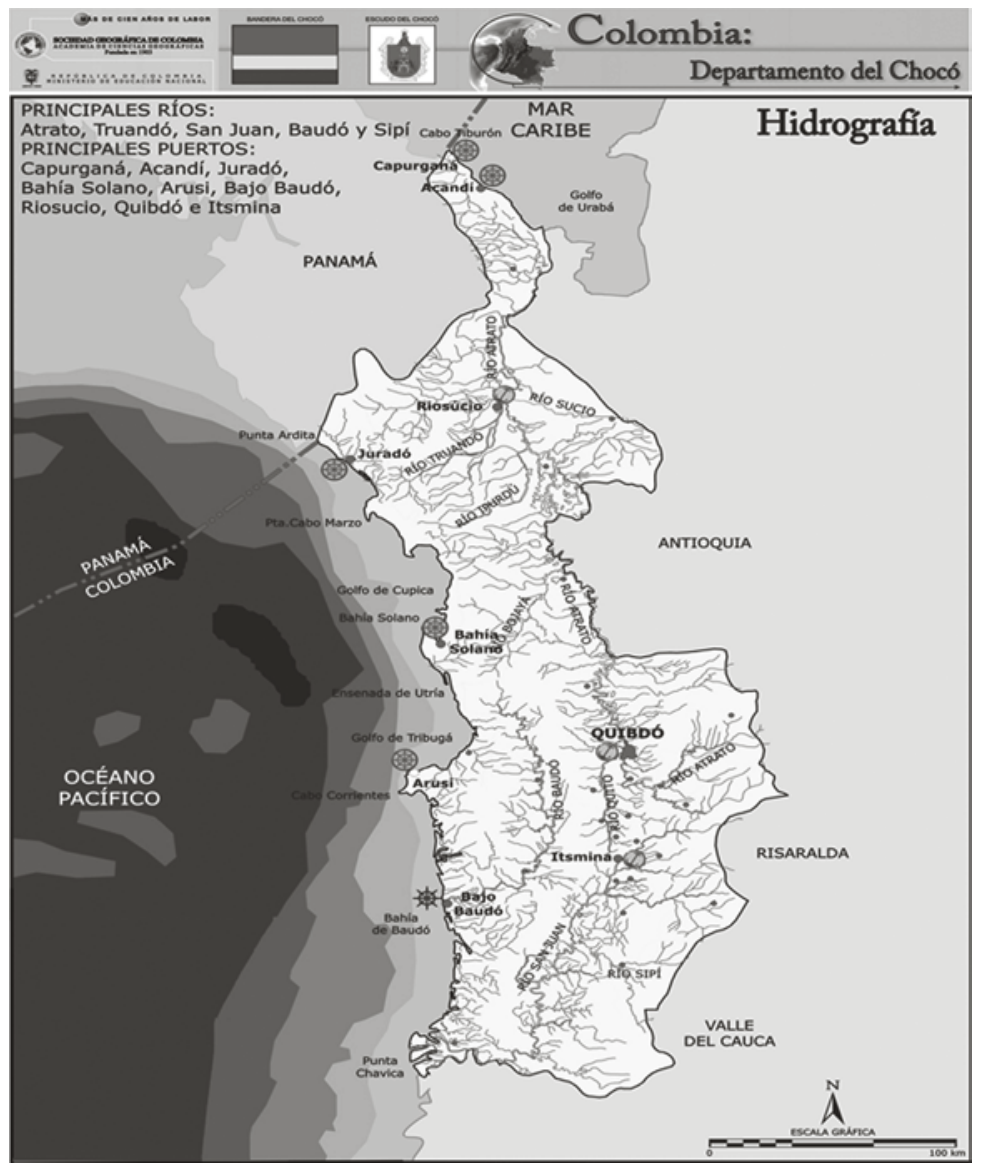

Figura 4.1 Hidrografía del departamento del Chocó. Fuente: IGAC (2002).

Asimismo, resaltan el peligro que puede acarrear, para una sociedad, tener instituciones permeadas por intereses corruptos por parte de los hacedores de política (Galvis, Moyano y Alba, 2016, p. 7). La misma teoría ha sido seguida por Acemoglu y Robinson en su libro Why Nations Fail. The Origins of Power, Prosperity and Poverty (2012), quienes explican cómo las instituciones son claves para el éxito de un país, argumentado que aquellas deben ser inclusivas y no extractivas. Por lo que consideran que el emprendimiento, la innovación y la verdadera creación de riqueza solo se dan en países inclusivos, circunstancia que, según los autores, está ausente no solo 
en Colombia, sino en América Latina. Si se siguen las líneas de los autores citados, la realidad es que el nivel de corrupción existente en el departamento del Chocó es desbordante, investigaciones recientes demuestran que:

en el departamento existe una relación perversa entre corrupción y crecimiento, que el proceso descentralizador se realizó bajo fundamentos poco estables que no garantizaron la transparencia de las entidades departamentales y el problema de la corrupción no ha hecho más que perpetuarse; por ello la región necesita un cambio de carácter estructural, donde se pueda garantizar el cubrimiento y alcance de la educación en todas las etapas para formar personas con carácter y criterio, para tomar las riendas y explotar en este departamento los beneficios potenciales que lo conducirán al crecimiento (Hoyos, 2015, p. 5).

Actualmente, es tan precaria la situación del departamento del Chocó que los resultados de algunos indicadores lo comparan con los de naciones en regiones deprimidas del mundo. Por ejemplo, el Consejo Nacional de Política Económica y Social (CONPES, 2005), tomando datos contrastados del Informe del Desarrollo Humano del PNUD (2003 citado en CONPES, 2005), expresa que, mientras en Bogotá, capital del país, el índice de desarrollo humano se asemeja a Hungría (país de alto desarrollo humano, puesto 38 en el mundo), el Chocó se asemeja a Kenia (país de bajo desarrollo humano, puesto 148 en el mundo). Nótese también que la tasa de mortalidad materna es de 357,97 mujeres fallecidas por cada 100.000 nacidos vivos. No solo es la más alta de Colombia, también supera a la de Ruanda (290) y Camboya (161), y casi iguala a la de Etiopía (353) ("Las cifras que tienen indignado al departamento del Chocó", 2016).

La línea de pobreza es el costo per cápita mínimo de una canasta básica de bienes (alimentarios y no alimentarios) en un área geográfica determinada. En 2014 la línea de pobreza en el departamento del Chocó fue de $\$ 183.843$ con aumento de 2,3\% con respecto a 2013, que fue de $\$ 179.7952$. Por tanto, un hogar en el Chocó compuesto por cuatro personas será clasificado como pobre si su ingreso está por debajo de \$735.372. De otro lado, teniendo en cuenta que la línea de pobreza extrema es el costo per cápita mínimo de una canasta alimentaria que garantiza las necesidades básicas calóricas; para el departamento de Chocó el valor de la línea de pobreza extrema en el 2014 fue de $\$ 87.762$, es decir, que un hogar de cuatro personas será clasificado 
como pobre extremo si su ingreso está por debajo de $\$ 351.048$ (DANE, 2015, p. 4).

La realidad también demuestra que la pobreza presente en el departamento tiene una estrecha relación con los estragos del conflicto armado, dada la proliferación de las guerrillas y el paramilitarismo en la región. Aquellos han sido factores transversales que contribuyen a que la población indígena y afrodescendiente sea una de las más afectadas por el fenómeno del desplazamiento forzado. Estos factores son:

(i) una exclusión estructural de la población afrocolombiana que la coloca en situación de mayor marginación y vulnerabilidad; (ii) la existencia de procesos mineros y agrícolas en ciertas regiones que impone fuertes tensiones sobre sus territorios ancestrales y que ha favorecido su despojo; y (iii) la deficiente protección jurídica e institucional de los territorios colectivos de los afrocolombianos (e indígenas), lo cual ha estimulado la presencia de actores armados que amenazan a la población afrodescendiente para abandonar sus territorios (Corte Constitucional, 2009).

La conclusión inmediata es que el Chocó, territorio perteneciente a 50.000 indígenas de las etnias emberá, katío, chamí, wounan y tule, y con alrededor de 400.000 afrocolombianos, hoy está acorralado o por la violencia o por el desplazamiento, o por las concesiones mineras o por la minería ilegal, o por el narcotráfico o por las fumigaciones áreas, o por la contaminación o por los actores armados ilegales, o por la fuerza pública o por la corrupción, o por la politiquería o por las enfermedades de la pobreza, o por inanición o por el mal sistema educativo y de salud; o por todos estos males juntos (Rodríguez y Durán, 2014, p. 3).

Factores que explican a profundidad que en el Chocó se ha permeado un estado de cosas, y todas en su conjunto han impactado no solo la economía, sino la cultura, pues diversas comunidades indígenas y tribales se encuentran en riesgo de extinción. Esto ha traído aparejado una consecuencia positiva, el empoderamiento y la lucha permanente de la población por el territorio, contexto que es necesario traer a colación para entender la tensión entre desarrollo, pobreza y riqueza, tan ambivalente y paradigmática en el departamento del Chocó. 


\section{LOS GRUPOS ÉTNICOS Y LAS LUCHAS POR EL TERRITORIO}

En el caso puntual, desde el siglo XIX hasta bien entrado el siglo XX el espíritu que motivaba las políticas del Estado, respecto al Pacífico continuaba siendo el de la colonia. El pacífico era considerado "tierra de indios" por tanto de "salvajes" a quienes era necesario civilizar (Proyecto Biopacífico, 1999, p. 2). Actualmente, lejos del estigma de la colonia, los grupos étnicos son sujetos colectivos que tienen derecho a lo propio: lenguas, creencias, usos y costumbres, protección y participación frente a la explotación de recursos naturales en sus territorios, reivindicando la apuesta política por el autogobierno.

Hecho que en Colombia se vio reflejado con la promulgación de la Constitución de 1991 y, posteriormente, con la entrada en vigor de la ley 70 de 1993, la cual, además de fundamentar como principio básico la propiedad colectiva de la tierra, de la cultura negra, garantiza también el reconocimiento y la protección de la diversidad étnica, cultural y el derecho a la igualdad de todas las culturas que conforman la nacionalidad colombiana.

En el caso de la cultura indígena, por ejemplo, es reconocido el contacto directo con la naturaleza y su estrecha relación con la tierra y el territorio como un derecho humano básico. Relación que puede expresarse de distintas maneras:

dependiendo del pueblo indígena particular del que se trate y de sus circunstancias específicas, puede incluir el uso o presencias tradicionales, la preservación de sitios sagrados o ceremoniales, asentamientos o cultivos esporádicos, recolección estacional o nómada, cacería y pesca, el uso consuetudinario de recursos naturales u otros elementos característicos de la cultura indígena o tribal (CIDH, 2009, p. 30).

Por esta razón, la Constitución de 1991 no solo integró los postulados del Convenio 169/89 de la Organización Internacional del Trabajo (OIT), relativo a los pueblos indígenas y tribales, sino que también garantizó jurisdicciones especiales, lo cual implica que las autoridades indígenas tienen la potestad de dirimir sus propias controversias. En la misma medida la constitución avaló una educación diferencial que asume el derecho a la educación según su cultura y cosmovisión. Todo lo cual ha sido el resultado de un cúmulo de luchas sociales que reivindican las voces de los movimientos sociales, activistas y sujetos titulares de derechos, que dialogan de igual a 
igual con el Estado, tejiendo participación en la vida política, económica y cultural, que antes estaba ausente, de los hoy denominados grupos étnicos.

Varios estudios internacionales han llegado a la conclusión que "los pueblos indígenas han sufrido históricamente discriminación y una de las mayores manifestaciones de esta discriminación ha sido el que las autoridades estatales no reconocieran las formas consuetudinarias indígenas de posesión y uso de las tierras" (CIDH, 2004, s. p.). Por tal razón, los grupos étnicos como sujetos colectivos empiezan a ser visibles para reivindicar no solo a los Estados, sino ante la misma comunidad internacional sus derechos humanos, la cual ya no tiene una tímida y limitada reflexión sino una visión evolutiva de los mismos. No obstante, debe precisarse que aún la entrada en vigor del Convenio 169 de la OIT

\begin{abstract}
se mantenían en las Américas procesos de despojo de tierras y territorios indígenas verificados desde el periodo colonial y a lo largo del periodo republicano. Ellos se expresaban en el avance de las fronteras agrícolas y de los procesos extractivos hacia los territorios indígenas particularmente - aunque no exclusivamente- en los países de la cuenca amazónica (Aylwin, 2014, p. 47).
\end{abstract}

Puede decirse que es con la humanización del derecho internacional que se materializa la defensa de los derechos humanos de los pueblos indígenas y tribales, quienes empiezan a tener una labor activa en la comunidad internacional, con reconocimiento no menos importante para intervenir activamente en las decisiones y actividades que les afectan, pues de lo que se trata

es de garantizar que los pueblos indígenas y tribales cuenten con la oportunidad de pronunciarse sobre aquellos proyectos o decisiones que puedan alterar sus formas de vida, incidir en su propio proceso de desarrollo o impactar, de cualquier manera, en sus costumbres, tradiciones e instituciones (Corte Constitucional, 2014).

Lo anterior, denominado como consulta previa, libre e informada, por el Convenio 169 de la OIT, es uno de los puntos cruciales que está generando grandes confrontaciones en el Estado colombiano: por un lado, la forma como se disfraza la consulta previa y, por el otro, la prevalencia de intereses personalísimos a nivel gubernamental, que intentan solapar las obligaciones internacionales que ya han sido contraídas, desconociendo el compromiso de proteger a los pueblos indígenas y tribales. 
$\mathrm{Al}$ respecto, la Organización Nacional Indígena de Colombia (ONIC), ha venido informando que de los 83 procesos de consulta previa realizados entre 1994 y 2009, "no existe un solo ejemplo de buenas prácticas en este tema" (ONIC, 2010, p. 17). Lo cual demuestra que, de forma restrictiva, se viene desarrollando una interpretación de la consulta previa, pues lo que debe ser un procedimiento serio, avalado constitucional y convencionalmente, termina siendo una conversación informal con los grupos indígenas y afrodescendientes, bastante aislada de las exigencias emanadas del Convenio 169. Desconociendo, además, que la convicción sobre la forma en que esa garantía de participación materializa otros derechos fundamentales, como su autonomía y su subsistencia, es justamente el punto de partida del deber de consulta que el Convenio 169 le impuso a sus Estados Parte (Corte Constitucional, 2014).

Por otra parte, en cuanto al reconocimiento de las comunidades negras, en Colombia fueron definidas en la ley 70 (1993):

como el conjunto de familias de ascendencia afrocolombiana que poseen una cultura propia, comparten una historia y tienen sus propias tradiciones y costumbres dentro de la relación campo-poblado, que revelan y conservan conciencia de identidad que las distinguen de otros grupos étnicos (art. 2).

Dicho reconocimiento no ha sido menos complejo; es más, con la Asamblea Nacional Constituyente de 1991 los participantes que lideraron la propuesta a favor del reconocimiento constitucional de los afrocolombianos se enfrentaron a la difícil tarea de identificar unos rasgos diferenciales que los caracterizaran como una colectividad digna de un trato especial coherente con el modelo de Estado democrático y participativo, que impulsaría la nueva Carta. Se trataba, ni más ni menos, de crear una categoría de alteridad étnica o un nuevo sujeto colectivo de derechos (Corte Constitucional, 2014).

Debe decirse, además, que la ley 70 de 1993 también se inspiró en el Convenio 169 de la OIT, toda vez que garantiza la protección de los terrenos respecto de los cuales ejercen el derecho a la propiedad colectiva sobre las áreas que comprenden las tierras baldías de las zonas rurales ribereñas de los ríos de la Cuenca del Pacífico y aquellas ubicadas en las áreas que vienen ocupando de acuerdo con sus prácticas tradicionales de producción. Siguiendo el artículo 4 de la citada ley, aquellas tierras son denominadas por derecho propio "Tierras de las Comunidades Negras". 
El eco-etnodesarrollo en el Chocó biogeográfico.

Estudio a partir del extractivismo y las luchas sociales por el territorio

Como se observa, Colombia es una nación muy diversa donde predomina el multiculturalismo, lo cual es producto

\begin{abstract}
del más variado mestizaje, donde interactúan la cultura y las tradiciones de los pueblos americanos, europeos y africanos; esta situación de diversidad la hace privilegiada respecto de los demás países del mundo. En este contexto se diferencian de la sociedad occidental cuatro sectores étnicos: los pueblos indígenas, las poblaciones afrocolombianas, incluidas las comunidades raizales de San Andrés y Providencia y la comunidad de San Basilio de Palenque, en el departamento de Bolívar y el pueblo rom o gitano (DANE, 2007, p. 19).
\end{abstract}

Sin embargo, debe decirse que los diferentes grupos étnicos en Colombia han tenido que fortalecerse en la militancia política, trabajando colectivamente en la defensa por su territorio, justamente por ser un elemento esencial que conecta su acervo cultural con su desarrollo.

Nótese que, aunque el Preámbulo de la Declaración del Derecho al Desarrollo consigna que sea un

proceso global, económico, social, cultural y político que tiende al mejoramiento constante del bienestar de toda la población y de todos los individuos, sobre la base de la participación activa, libre y significativa en el desarrollo y en la distribución justa de los beneficios que de él se derivan (Organización de las Naciones Unidas, 1986),

no siempre las estrategias, acciones y planes, concretados en política públicas, entienden la estrecha relación de colectivos específicos con sus territorios; lo cual hace que su afectación no sea menor, teniendo en cuenta las diferentes dinámicas que se han mantenido en el Estado colombiano desde tiempos pasados.

En el caso del Chocó, por ejemplo, los grupos étnicos se han visto afectados no solo por la dinámica del conflicto armado, sino por el uso y abuso de sus recursos naturales. Estudios en la materia confirman que las comunidades han quedado en un estado de incertidumbre en relación con el control que pueden mantener sobre la tierra concedida por proceso de restitución, así lo revela el caso del Consejo Comunitario Mayor de la Organización Popular Campesina del Alto Atrato (COCOMOPOCA), pues ha sido objeto de abandono a partir de las acciones de los grupos armados que buscan establecer su control militar. Lo que ha propiciado la entrada de ter- 
ceros que se aprovechan de la vulnerabilidad de la población para realizar sus actividades extractivas, sin tener en cuenta la organización política y sus procesos de consulta (Unidad de Restitución de Tierras, 2014).

COCOMOPOCA se compone de 43 comunidades afrocolombianas del Chocó (oeste de Colombia), cuyo control de tierras ancestrales ha sido amenazado durante décadas de conflicto. En 1999, las comunidades solicitaron un título de propiedad colectiva de conformidad con la ley 70 (1993) a fin de obtener el título sobre sus tierras. Después de esta solicitud, sufrieron desplazamiento forzado, amenazas y asesinatos. Como explica un líder comunitario de COCOMOPOCA: -Es horrible vivir con tanto miedo, la guerrilla y los paramilitares mataron a gente en mi familia. La gente me mira y me sigue. Es difícil de explicar lo mal que está la situación-.

Cuando recibieron el título de propiedad por 73.000 hectáreas, menos de la mitad de las 172.000 hectáreas de tierras ancestrales que figuraban en su solicitud, descubrieron que se había otorgado a la AngloGold Ashanti (AGA), una concesión minera por 50.000 hectáreas de esas 73.000 del título. Esto viola directamente el derecho al consentimiento libre, previo e informado que tienen que prestar para las actividades en sus tierras, de acuerdo a lo establecido en el Convenio 169 (ABColombia, 2012, pp. 8-9).

La situación de COCOMOPOCA no es el único ejemplo que ilustra el contexto enunciado; el caso de las comunidades afrodescendientes desplazadas de la cuenca del río Cacarica, más conocido como "Operación Génesis" en el departamento del Chocó, contiene herramientas de análisis que merecen ser descritas, no solo por la gravedad de los derechos humanos violados, sino por la especificidad en la afectación al territorio.

En el caso enunciado resalta que las víctimas eran miembros de comunidades afrodescendientes que se asentaron en la cuenca del Cacarica en un proceso de búsqueda de tierras, luego de la abolición de la esclavitud a mediados del siglo XIX, momento a partir del cual se inició un proceso migratorio desde el sur del Pacífico de Colombia hacia el sur del Chocó, luego al medio y bajo Atrato. Aunque la población vivía en condiciones de pobreza, pues básicamente subsistía de los cultivos de pancoger, de la pesca artesanal, de la caza y de la explotación maderera, tuvo que soportar en su territorio no solo la presencia de diversos grupos armados al margen de la ley, acompañada de amenazas, asesinatos y desapariciones, que originaron 
su desplazamiento, sino que soportó, además, "la actuación ilegal de las empresas Maderas del Darién S. A. y Pizano S. A., mediante el otorgamiento de permisos de extracción, la legalización de la madera a través de mecanismos irregulares y la contribución al enriquecimiento de terceros" (Corte IDH, 2013, p. 60).

El caso evidencia cómo las comunidades afrodescendientes del Cacarica tienen "una relación con el territorio casi umbilical, una relación vital perceptible en las palabras según las cuales el territorio es su madre y es su padre porque de él reciben todos los beneficios" (Corte IDH, 2013, parágrafo 340). Sin embargo, con la Operación Génesis las víctimas fueron arbitrariamente despojadas del uso y goce de sus bienes, pues el desplazamiento estuvo acompañado del saqueo y la destrucción de bienes individuales y colectivos. Es clave resaltar, también, que la injerencia violenta, la ocupación y destrucción de sus espacios de vida íntima y comunitaria, de sus lugares de habitación y de siembra, afectó profundamente su forma de vida y sobrevivencia, su cultura e identidad ancestral:

El territorio del que fueron desplazados fue ilegalmente aprovechado por empresas de extracción [de] madera, mientas el territorio estaba controlado por grupos paramilitares que impedían el regreso de sus habitantes ancestrales. [...] Estas empresas realizaron un uso irracional en forma mecanizada de los recursos maderables del Cacarica, que ha generado un profundo daño en el territorio, los recursos forestales y en las condiciones de vida de las minorías étnicas que habitan las zonas de extracción (Corte IDH, 2013, parágrafo 341).

Lo anterior posibilitó, ante las violaciones sistemáticas de los derechos humanos reflejadas no solo en el desplazamiento, sino en la destrucción de su identidad cultural por el arrasamiento ambiental de sus territorios por prácticas empresariales, que las comunidades afrocolombianas de Cacarica y de otros municipios como Curbaradó y Jiguamiandó (Chocó) construyeran alternativas de sobrevivencia en su territorio llamadas zonas humanitarias y zonas de biodiversidad (Bouley y Rueda, 2007). No obstante, lo expuesto evidencia que las prerrogativas implícitas en la constitución y las obligaciones derivadas del Convenio 169 no son suficientes para terminar con la afectación que sufren diferentes grupos étnicos en sus territorios.

Como se estudiará en el acápite siguiente, el territorio es un elemento vital para la conservación y subsistencia. Visto de manera multidimensio- 
nal involucra el entorno donde interactúan diversos sujetos, instituciones y diferentes grupos sociales, de manera individual o colectiva, en un ámbito geográfico determinado en el que se comparten símbolos, creencias y representaciones, lo cual influye en la articulación de factores culturales, económicos, sociales y, por supuesto, está ligado al desarrollo, pues los sujetos inmersos junto a la actividad económica en la que se centran, instituyen las bases para el mantenimiento de una colectividad determinada.

\section{APROXIMACIÓN EPISTEMOLÓGICA AL CONCEPTO DE TERRITORIO}

Aunque hablar del territorio es una cuestión tan antigua como la propia historia humana, como concepto - visto desde de diferentes disciplinas - ha tenido múltiples acepciones a lo largo de la historia, al tiempo que su significado ha tenido variaciones, transformaciones y usos indistintos. Por ello, es necesario aclarar que hablar de territorio no es sinónimo de tierra, lo cual no quiere decir que no sean conceptos relacionados entre sí. Es a partir de la década del 2000 que el concepto de territorio "sea por razones epistemológicas, sea por motivos epistemofílico, (por considerar que 'hay que usarlo') se fue difundiendo en las ciencias sociales y fue ampliamente incorporado en los estudios sociológicos, antropológicos e históricos" (Benedetti, San Cristóbal, Mereb, Salizzi, Fabregas y Gatti, 2011, p. 12).

Para entender el territorio, advierte Sosa (2012), es necesario establecer su carácter en tanto relación geo-eco-antrópica multidimensional.

La configuración del territorio se entiende a partir de su condición de marco de posibilidad concreta en el proceso de cambio de los grupos humanos. Sin embargo, también es el resultado de la representación, construcción y apropiación que del mismo realizan dichos grupos, así como de las relaciones que lo impactan en una simbiosis dialéctica en la cual tanto el territorio como el grupo humano se transforman en el recorrido histórico (p. 7).

En ese sentido, insiste Sosa (2012), "el territorio no es solamente una porción de tierra delimitada con su complejidad biofísica (relieve, condiciones ambientales, biodiversidad). Es, sobre todo, un espacio construido socialmente, es decir, histórica, económica, social, cultural y políticamente" (p. 7). Por lo tanto, el territorio, al contrario del espacio físico, es una significación cultural con variadas implicaciones a nivel social (Nates, 2011). Está 
estructurado y organizado en su espacialidad por medio de relaciones entre los seres humanos y los demás elementos que contiene (Montoya, 2006).

Para designar esos espacios los hombres han elegido diversas estructuras o elementos característicos para hablar verbigratia de ciudades, municipios, veredas, corregimientos, regiones, provincias, comunas, etc. Lugares donde están asentadas colectividades. Por ello, como expresa Bajoit (2003), el espacio reviste una importancia capital para la estructuración de las identidades colectivas: las identidades territoriales son a menudo las más movilizadoras y resistentes a los cambios. El territorio termina siendo, en pocas palabras, un espacio apropiado, posición asumida por Raffestin (2011), y seguida también por Porto, (2009) y Giménez (1996), donde no solo interactúan los seres humanos, sino que emergen conflictos.

El territorio es entonces una manera de aprehender, conceptualizar y apropiarse de parte o de la totalidad del espacio social en el que se vive (Damonte, 2011). En él, a su vez, surgen dinámicas colectivas y relaciones de subordinación; de hecho, las "imágenes" territoriales revelan relaciones de producción y, en consecuencia, relaciones de poder. Del Estado al individuo, pasando por todas las organizaciones, grandes o pequeñas, se encuentran los actores sintagmáticos que "producen" el territorio. El Estado trata de organizar sin cesar el territorio nacional haciendo nuevos cortes, nuevas implantaciones y nuevos enlaces territoriales (Raffestin, 2011). De tal suerte, que las dinámicas que surgen en relación al territorio también están asociadas a las luchas sociales, en el entendido que, "oficialmente", sería un espacio social cuyo diseño y límites han logrado poder hegemónico, mientras el diseño territorial contra-hegemónico sería el subversivo (Damonte, 2011).

Por otra parte, Reboratti (2001) explica "el territorio a partir de un 'archivo' de sucesos ocurridos a lo largo del tiempo, que van dejando rastros que se superponen en una especie de palimpsesto" (s. p.). En este escenario, el territorio, según lo explicado por Bello (2004), acudiendo a George de Vos (1995), aparece como "un factor de cohesión social para los grupos étnicos, aun cuando existan grupos que han perdido el control sobre este o posean una mínima parte de lo que consideran su territorio histórico" (s. p.). De este modo, el territorio es un concepto estrechamente ligado a la defensa de la identidad étnica, ya sea de manera simbólica o material. El territorio también aparece como "imagen, como representación, siendo un instrumento de poder. En el contexto de los procesos sociales, las representaciones son motores de la acción colectiva, guías que incluso se superponen al objeto mismo representado" (Bello, 2004, p. 99). Así pues, las representaciones del 
territorio son fundamentales para comprender los procesos de construcción territorial, así como sus formas de apropiación.

Retomando a Sosa (2012), este resume las acepciones explicadas desde tres dimensiones dignas de mención.

Desde una dimensión social, donde los territorios son sistemas cuya organización y límites se negocian al fragor de las relaciones sociales, marco en el cual los actores o sujetos lo construyen combinando lo concreto pensado (la representación que se tenga sobre el territorio) con lo concreto real (la relación que se desarrolla con este). Los actores lo ocupan, lo utilizan, lo organizan, lo transforman y, en síntesis, lo construyen en la búsqueda de su reproducción social, de un sentido de pertenencia como posesión o como identidad y de acciones relacionadas con el dominio sobre el mismo (p. 26).

Esa configuración social del territorio también tendrá otros factores intervinientes, como el étnico. Más allá de la importancia poblacional que pueda tener la diversidad étnica, en donde habrá territorios monoétnicos, multiétnicos o con presencia mayoritaria de alguna configuración sociocultural, esta diferencia se constituye en factor, regularmente, para el establecimiento de ámbitos posibles de relación social y fronteras sociales que pueden traducirse en prácticas de apropiación del territorio (p. 38).

Así, territorio e identidad estarían estrechamente ligados y se retroalimentarían de manera permanente. Esta integración entre el territorio y la subjetividad de la vivencia identitaria se produciría sobre todo cuando los grupos sociales adquieren una conciencia de sí mismos (Bello, 2004).

Desde la dimensión económica, Sosa (2012) describe que:

el territorio se refiere a las características, dinámicas y procesos económicos (en distintas escalas de relación) que actúan como determinantes o estructuradores territoriales [...]. Puede entenderse como un ámbito o un escenario específico de producción, intercambio, distribución y consumo en el contexto de una formación social concreta (p. 49).

Finalmente, la dimensión política se refiere al ejercicio de poder que se traduce en constantes y complejos procesos y dinámicas de lucha por la posesión y control del territorio que, a su vez, se convierten en apropiaciones, construcciones y transformaciones territoriales (p. 71). 
En suma, haciendo trascender estas formas de poder local/étnico en los actuales procesos de acumulación de capital y de nuevas y renovadas imposiciones desde lo global y lo nacional, en el territorio como configuración socio-étnica están registrándose articulaciones entre pueblo indígena, territorio y demandas de derechos con cierta orientación a reivindicar el derecho madre de los pueblos indígenas: la libre determinación. Esta articulación de nociones, más allá de su utilización discursiva, sustenta procesos de resistencia en donde se vinculan identidades, la exigencia para el uso y goce de recursos naturales y la reivindicación del territorio como espacio de jurisdicción étnica y local (p. 91).

Posición que es necesaria para entender la constante lucha desplegada por las comunidades étnicas en el contexto colombiano, ante un panorama donde el territorio trasciende como estructura social y se convierte en un derecho humano.

\section{Despojo, extractivismo y eco-etnodesarrollo}

Hay evidencia científica que, desde 1923 hasta 1974, la Compañía Chocó Pacífico construyó una hidroeléctrica, cuyo principal objetivo era generar energía suficiente para el funcionamiento de las dragas que explotaban los recursos de oro y platino. Aunque también suplieron de energía a poblaciones aledañas, para los pobladores asentados en el río Andágueda la obra les representó cambios significativos, pues afectó la cotidianidad de los pobladores, incidió en los conflictos por la tierra, persiguió a la minería artesanal, y despojó de los derechos sobre el territorio a los pobladores ancestrales (Unidad de Restitución de Tierras de Quibdó, 2014).

Pero más adelante, con la aparición de las guerrillas en Colombia, alrededor de 1960, el panorama es otro. Con la llegada del desplazamiento forzado, producto del conflicto armado, y con este los grupos armados, reaparece la disputa territorial en el esfera rural con diversos aspectos ligadas entre sí: cultivos ilícitos, el concurso de las multinacionales, los intereses económicos articulados al mercado global, las bandas criminales emergentes, el paramilitarismo, la delincuencia común, los conflictos históricos por la tenencia y explotación económica de la tierra, el despojo, uso y abuso del suelo, y la minería ilegal, muy especialmente, influyendo en detrimento de los territorios de comunidades afrodescendiente, indígenas y tribales, afec- 
tando no solo sus prácticas ancestrales, sino el propio desarrollo humano de las personas que los habitan.

El comunicado de la Comisión Interamericana de Derechos Humanos (2015), ratifica que "las personas afrodescendientes en Colombia continúan siendo víctimas de desplazamiento forzado interno en forma desproporcionada, como resultado del conflicto armado en sus territorios ancestrales y de sus actividades y proyectos de desarrollo relativos a industrias extractivas" (p. 169). Adicionalmente, como sustenta dicho comunicado, "las personas afrocolombianas han sido excluidas históricamente de las decisiones y los procesos sobre cómo reparar y remediar las violaciones a los derechos humanos que emergen del desplazamiento y del conflicto" (CIDH, 2015, s. p.).

Lo cierto es, que los responsables del abandono y despojo de tierras, en el marco de la justicia transicional, conforme a lo acordado en La Habana, según el numeral 1.10 del Acuerdo de Paz, han conciliado sobre el cierre de la frontera agrícola y protección de zonas de reserva, con el propósito de proteger las áreas de especial interés ambiental y generar, para los pobladores que colindan con ellas o las ocupan, alternativas equilibradas entre medio ambiente, bienestar y buen vivir, bajo los principios de participación de las comunidades rurales y desarrollo sostenible.

Sin embargo, a pesar de lo acordado aparecen otras amenazas institucionales: la ley 1776 (2016), más conocida como la Ley Zidres, por la cual se crean y se desarrollan las Zonas de Interés de Desarrollo Rural, Económico y Social para zonas que se encuentren aisladas de los centros urbanos más significativos; demanden elevados costos de adaptación productiva por sus características agrológicas y climáticas, tengan baja densidad poblacional, presenten altos índices de pobreza o carezcan de infraestructura mínima para el transporte y comercialización de los productos.

En relación con la ley, hay quienes argumentan que es un claro ejemplo de un

proyecto que comanda la ofensiva de burguesía (colombiana y extranjera) por apropiarse de tierras de frontera, y por tanto de rentas (agrícolas y energéticas), generadas sin duda por la globalización de la economía, ya que el precio del aceite combustible es un reflejo de la producción mundial de la palma de aceite y, en el fondo, del precio de los hidrocarburos, sucedáneos en ciertas condiciones del aceite vegetal y del alcohol carburante (Álvarez, 2016, p. 444). 
Nótese que el cultivo de palma africana como megaproyecto agroindustral está siendo impulsado fuertemente en varias áreas de Colombia, cuyas características edafoclimáticas coinciden con los requerimientos óptimos necesarios para desarrollar cultivos de alta rentabilidad. Una de estas zonas es el Chocó (Mingorance, Minelli y Le Du, 2004).

La Ley Zidre genera serios cuestionamientos, en tanto promueve que empresarios realicen proyectos productivos en alianza con comunidades campesinas o étnicas, teniendo en cuenta, como explica la ACNUR (2014), que en Colombia, en las regiones más alejadas, persiste el conflicto armado y en algunas las áreas que se seleccionarán para concretar esta iniciativa estarían solicitadas en restitución de tierras, o serían reclamadas por comunidades étnicas. Es más, obsérvese que:

De las 1,2 millones de hectáreas que indígenas y afrodescendientes reclaman en los departamentos de Nariño, Cauca, Chocó y La Guajira, hasta el momento solo se ha proferido un fallo por el Tribunal Superior de Antioquia a favor de los indígenas emberá-katíos del Alto Andágueda, en el Chocó. Lo trascendental es que se ordenó, además, ponerle freno a la minería ilegal, así como a la concesión minera adelantada por la Agencia Nacional de Minería en esta zona, que se opuso a la restitución (Verdadabierta, 2014, s. p.).

Como se puede observar, los múltiples fenómenos que permanecen en los territorios de grupos étnicos chocoanos arrojan evidencias de los grandes retos que deben superase en pro de conciliar los intereses particulares y los colectivos, para no privilegiar los intereses del mercado bajo la ideología del sistema capitalista, donde prima la producción, distribución y consumo, sin medir los efectos devastadores sobre los elementos que conforman el ecosistema.

Es aquí donde la noción de eco-etno-desarrollo juega un papel crucial, entendida como una postura contrahegemónica que implicaría pensar, repensar y des-pensar la quimera del capitalismo para construir una visión del desarrollo más humanizante, basada en el respeto al medio ambiente, valorando el papel que juegan los grupos étnicos en dicha transformación. Análisis, quizás, puesto en boga por primera vez a partir de la Declaración de San José, sobre etnodesarrollo y etnocidio en América Latina, en 1981. 
En dicha declaración

Entendemos por etnodesarrollo como la ampliación y consolidación de los ámbitos de cultura propia, mediante el fortalecimiento de la capacidad autónoma de decisión de una sociedad culturalmente diferenciada para guiar su propio desarrollo y el ejercicio de la autodeterminación, cualquiera que sea el nivel que considere, e implican una organización equitativa y propia del poder. Esto significa que el grupo étnico es unidad político-administrativa con autoridad sobre su propio territorio y capacidad de decisión en los ámbitos que constituyen su proyecto de desarrollo dentro de un proceso de creciente autonomía y autogestión (Declaración de San José, 1981, p. 24).

Debe decirse, por tanto, que en las sociedades multiculturales los procesos de globalización también alteran los ritmos nacionales de la economía y la política, con profundas contradicciones que atentan contra las bases del desarrollo humano (Arriola, 2007), por lo que la alerta permanece: si los sistemas de valores dominantes legitiman y justifican ciertas prácticas y no otras, se corre el riesgo de caer en la regresividad de los derechos económicos, sociales y culturales, por estrategias del mercado. Dicho de otro modo, será el poder hegemónico quien imponga las rutas a seguir en el modelo de "desarrollo". Ahora bien, el concepto de desarrollo nace sesgado por cuenta del etnocentrismo, la cultura y los valores anglosajones. Para ellos la pobreza se asocia a carencias o deficiencias de la persona, y por la vía del mercado y del sistema capitalista de producción van a moldear el desarrollo de estos países sin tener en cuenta las culturas de muchos pueblos y etnias, donde los conceptos de riqueza y pobreza son relativos y los conceptos de frugalidad, comunidad y suficiencia servían para afrontar el problema de la pobreza (Santacruz, 2006).

Así, la realidad demuestra que el sistema de valores hegemónico en nuestros días es mayoritariamente neoliberal y, por consiguiente, pone por encima a las libertades

funcionales al mercado y por debajo a las políticas públicas de igualdad social, económica y cultural. De este modo, la aplicación efectiva de las normas reconocidas en las Constituciones o en los diferentes ordenamientos jurídicos no van a poder ser aplicadas en beneficio de un acceso igualitario a los bienes, sino en función de los "valores" que se postulan desde dicho sistema económico, que tanta influencia ha tenido en el desmantelamiento de lo que en la Constitución se denomina Estado Social (Herrera, 2008, p. 36). 
El resultado será el soporte de una:

teoría económica ortodoxa neoliberal sustentada sobre los valores del egoísmo, el interés individual contrapuesto al interés social o interés general, la avaricia, la necesidad de tener, acumular y crecer, la vanidad, poseer y consumir la última novedad del mercado, y la envidia, no ser menos que nadie. El resultado es una sociedad de individualidades solitarias, consumistas, competitivas, depresivas e infelices (Moreno, 2011, p. 168).

Afirmación que evoca que, para la satisfacción de unos estándares mínimos de bienestar, se debe impulsar el desarrollo humano en pro de elevar la calidad de vida de las personas, no al contrario, poner los derechos humanos en deterioro a costa del crecimiento económico. Por ello, se debe abordar el desarrollo desde una perspectiva emancipadora que concilie la propuesta del Estado Social para generar el máximo de bienestar posible

ante la progresiva ocupación de espacios por poderosas fuerzas económicas y sociales [...] que se extienden no solo en territorios, sino también en las relaciones económicas, políticas, y culturales, produciendo, paradójicamente quizás, mayores desigualdades que deciden la calidad de vida de unos y otros (Pegoraro, 2013, p.21).

\section{Principales hallazgos}

Teniendo en cuenta lo explicado surgen varias propuestas dignas de mención: es una necesidad poner freno y límites a este estado de cosas que van en detrimento de los territorios y los derechos humanos de las personas que los habitan, ante las paradojas suscitadas en torno al desarrollo, a la par de los contextos de violencia que agravan la situación en el caso colombiano. Particularmente, como se observó, por la afectación que padecen diversos grupos étnicos en sus territorios. Situación que pone en elevado riesgo la extinción de poblaciones indígenas y tribales, lo cual trae aparejado, a su vez, pérdida de identidad cultural.

Concluyentemente, las necesidades de los grupos étnicos en Colombia, aún con el surgimiento de la ley 70 de 1993 no han sido del todo entendidas, atendidas, ni abordadas. Cuestión que se empeora dada la tensión entre desarrollo y límites ambientales; el fenómeno del extractivismo lo comprueba. Por ende, aún los intentos, hasta que no se entienda la necesidad de re- 
pensar el desarrollo, per se, a partir de finalidades social y ambientalmente armónicas, en un contexto en el que el crecimiento económico es un efecto secundario y no la variable central (Delgado, 2011), muy difícilmente se podrá llegar a un consenso no solo local, regional, nacional, e incluso mundial, sobre la conservación ambiental, con todo lo que ello implica, para formular propuestas para una adecuada economía del bienestar que se centre, como su nombre lo indica, en el análisis del bienestar asociado al uso oportuno y necesario de los recursos limitados, advirtiendo la simetría ineludible en la implementación de estrategias, programas, planes y, en suma, políticas públicas encaminadas a la búsqueda primaria del bienestar humano.

La idea es, pues, en el contexto colombiano, no solo luchar contra las dinámicas tradicionales, asociadas al conflicto armado, sino también contra los excesos del capitalismo, toda vez que como sistema tiende a ocultar que la verdadera causa de los problemas reside en una dinámica circular que parte de los siguientes procesos:

1) La apropiación privada de todos los recursos naturales y humanos; 2) la "construcción" de escasez de recursos que impone la apropiación privada de los mismos; 3) la imposición de un mercado autorregulado como forma privilegiada de distribuir recursos "convertidos" en escasos; y 4) la acumulación de capital como objetivo último que permita volver a iniciar este circuito infernal con la nueva fase de apropiación (Herrera, 2006, p. 191).

Es por esta razón que, en esencia, se deben vincular otras rutas para construir fórmulas para el bienestar humano que tengan como punto de partida el entendimiento básico sobre la estrecha relación que tienen las comunidades afrodescendientes, indígenas y tribales, con el territorio, pese al abandono estatal evidenciado, en este caso, en el departamento del Chocó. Dichas rutas deben contribuir, de manera especial, a la comprensión de la relación intrínseca que tienen dichas comunidades respecto a su territorio, como una cuestión de supervivencia ante los diferentes factores que fragmentan el hacer humano, promoviendo diferentes formas de exclusión. La relación lamentable entre despojo, extractivismo y destierro de poblaciones indígenas y afrodescendientes, por la dinámica entre el desplazamiento forzado, el narcotráfico, la guerrilla y el paramilitarismo, en el marco del conflicto armado, es prueba de ello.

La verdad es que los movimientos sociales con alianzas y sinergias pueden poner límite al poder económico dominante, fijando a su vez frenos 
a los excesos del sistema capitalista para la concreción de un verdadero desarrollo humano, al tiempo que construir caminos para el mantenimiento de sociedades democráticas y sustentables en términos de conservación. De hecho, los factores políticos, sociales, ambientales y económicos van de la mano en la construcción de vías de acceso para la conservación del entorno.

Finalmente, debe ser un parámetro básico ser conscientes que nuestras posibilidades estarán limitadas si no emerge un cambio de perspectiva, cambio que debe involucrar una adecuada utilización de la naturaleza, lejos de concepciones antropocentristas, tomando posturas contrahegemónicas ante las desigualdades sociales existentes pues, como se pudo observar, en el Chocó, hay diversos factores que impiden la salida a la pobreza y, por el contrario, abundan elementos que la perpetúan, a la par que amenazan el equilibro ambiental, por el uso y abuso de los recursos naturales.

\section{REFERENCIAS}

ABColombia (2012). El panorama actual de Colombia: ley de víctimas y restitución de tierras ley 1448. Recuperado de https://www.abcolombia.org.uk/wp-content/uploads/2012/05/Colombia-the-Current-Panorama_Spanish.pdf

Acemoglu, D. \& Robinson, J. (2012). Why Nations Fail. The Origins of Power, Prosperity and Poverty. Nueva York: Crown Publisher.

Almario, O. (2004). Dinámica y consecuencias del conflicto armado colombiano en el Pacífico: limpieza étnica y desterritorialización de afrocolombianos e indígenas y "multiculturalismo" de Estado e indolencia nacional. En E. Restrepo y A. Rojas (Eds.), Conflicto e (in)visibilidad. Retos en los estudios de la gente negra en Colombia (pags. 73-120). Cali: Editorial Universidad del Cauca.

Álvarez, C. (2016). Colombia: la negociación de la tierra en La Habana. En J. Estay (Coord.), La economía mundial y América Latina ante la continuidad de la crisis global (pags. 443-471). Puebla: Benemérita Universidad Autónoma de Puebla.

Amnistía Internacional (2010). La lucha por la supervivencia y la dignidad. Abusos contra los derechos humanos de los pueblos indígenas en Colombia. Recuperado de http://www.acnur.org/t3/uploads/media/COI_2753.pdf

Amnistía Internacional (2016). La situación de los derechos humanos en Colombia. Declaración escrita ante el Consejo de Derechos Humanos de 
la ONU en su $31^{\circ}$ periodo de sesiones. Recuperado de https://www.colectivodeabogados.org/IMG/pdf/amr2333412016spanish.pdf

Arriola, G. (2007). Desarrollo humano: una introducción conceptual. Guatemala: Programa del Informe Nacional de Desarrollo Humano.

Aylwin, J. (2014). Los derechos de los pueblos indígenas sobre la tierra y el territorio en América Latina y el Convenio 169 de la OIT. En J. Aylwin y L. Tamburini (Eds.). Convenio 169 de la OIT: los desafíos de su implementación en América Latina a 25 años de su aprobación (pags. 4461). Copenhague: Grupo Internacional de Trabajo sobre Asuntos Indígenas, IWGIA.

Bajoit, G. (2003). Todo cambia: análisis sociológico del cambio social y cultural en las sociedades contemporáneas. Santiago de Chile: LOM Ediciones.

Bello, Á. (2004). Etnicidad y ciudadanía en América Latina. La acción colectiva de los pueblos indígenas. Santiago de Chile: CEPAL.

Benedetti, A., San Cristóbal, D., Mereb, J. F., Salizzi, E., Fabregas, M., y Gatti, I. (2011). Territorio, lugar, paisaje: prácticas y conceptos básicos en geografía. Buenos Aires: Facultad de Filosofía y Letras, Universidad de Buenos Aires.

Bodnar, Y. (2006). Colombia: apuntes sobre la diversidad cultural y la información sociodemográfica disponible en los pueblos indígenas. En Pueblos indígenas y afrodescendientes de América Latina y el Caribe: relevancia y pertinencia información sociodemográfica para políticas y programas (pags. 1-20). Santiago de Chile: CEPAL. Recuperado de http://200.9.3.103/ mujer/noticias/noticias/5/27905/YBodnar.pdf

Bonet, J. (2009). ¿Por qué es pobre el Chocó? Documentos de trabajo sobre economía regional, (90), 1-64. Recuperado de http://www.banrep.gov. co/sites/default/files/publicaciones/archivos/DTSER-90.pdf

Bouley, C., y Rueda, D. (2007). Zonas humanitarias y zonas de biodiversidad: espacios de dignidad para la población desplazada en Colombia. Recuperado de jyp.megadatesystem.com/IMG/pdf/Uexternado_Finalvb.pdf

Casas, F. (1994). Proyecto Biopacífico: hacia una cultura de la biodiversidad en el Pacífico colombiano. En M. Rodríguez (Ed.), La política ambiental del fin de siglo: una agenda para Colombia (pags. 152-181). Bogotá: CEREC.

Centro Nacional de Memoria Histórica (2015). Una nación desplazada. Informe nacional del desplazamiento forzado en Colombia. Bogotá: CNMH - UARIV. 
Corte Constitucional de Colombia (2009). Auto 005, M. P. Manuel Cepeda Espinosa, Bogotá. Recuperado de http://www.corteconstitucional. gov.co/relatoria/autos/2009/a005-09.htm

Corte Constitucional de Colombia (2014). Sentencia T-576. M. P. Luis Ernesto Vargas Silva, Bogotá. Recuperado de http://acmineria.com.co/sites/ default/files/regulations/t-576-14_-_corte_constitucional_afros.pdf

CIDH (2004). Comunidades Indígenas Maya del Distrito de Toledo, Caso 12.053 (Belize), Informe N..$^{\circ}$ 40/04. Recuperado de https://www.cidh. oas.org/annualrep/2004sp/Belize.12053.htm

CIDH (2009a). La situación de los grupos étnicos en Colombia. Recuperado de http://www.cidh.oas.org/annualrep/2009sp/cap.4colo.09.sp.htm

CIDH (2009b). Derechos de los pueblos indígenas y tribales sobre sus tierras ancestrales y recursos naturales: normas y jurisprudencia del sistema interamericano de derechos humanos. Recuperado de https://www.oas.org/ es/cidh/indigenas/docs/pdf/tierras-ancestrales.esp.pdf

CIDH (2013). Caso de las comunidades afrodescendiente desplazadas de la cuenca del río Cacarica (operación génesis) vs. Colombia. Sentencia de 20 de noviembre de 2013.

Recuperado de http://www.corteidh.or.cr/docs/casos/articulos/seriec_270_esp.pdf

CIDH (2015a). Pueblos indígenas, comunidades afrodescendientes y recursos naturales: protección de derechos humanos en el contexto de actividades de extracción, explotación y desarrollo. Recuperado de http://www. oas.org/es/cidh/informes/pdfs/IndustriasExtractivas2016.pdf

CIDH (2015b). Comunicado de prensa 95/15 sobre la situación de los afrodescendientes en Colombia. Recuperado de http://www.oas.org/es/cidh/ prensa/comunicados/2015/095.asp

Congreso de la República (1993). Ley 70. Por la cual se desarrolla el artículo transitorio 55 de la Constitución Política. Recuperado de http:// www.urosario.edu.co/Universidad-Ciencia-Desarrollo/ur/Fasciculos-Anteriores/Tomo-I---2006/Fasciculo-4/pdf/2006_fa04_Ley_70-93/

Consejo Nacional de Política Económica y Social (2005). (CONPES) Metas y estrategias de Colombia para el logro de los objetivos de desarrollo del milenio - 2015. Recuperado de http://www.colombiaaprende.edu.co/ html/familia/1597/articles-305252_compes091.pdf

Corporación Humanas Colombia (2015). Situación de las mujeres afrocolombianas e indígenas. Colombia 2011-2014. Bogotá: Ediciones Ántropos. 
Damonte, G. (2011). Construyendo territorios: narrativas territoriales aymaras contemporáneas. Lima: CLACSO.

Departamento Administrativo Nacional de Estadística (2005). Censo General. Recuperado de www.dane.gov.co/index.php/estadisticas-por-te$\mathrm{ma} / . . .2005-1 /$ censo-general-2005

Defensoría del Pueblo (2016). Problemática humanitaria en la región pacífica colombiana. Bogotá, Defensoría Delegada para la Prevención de Riesgos de Violaciones a los Derechos Humanos y DIH. Recuperado de http://www.defensoria.gov.co/public/pdf/Informepacificoweb.pdf.

Delgado, G. (2011). Decrecimiento biofísico y desarrollo. Revista Desarrollo Local Sostenible, 4(10), 1-11. Recuperado de http://www.eumed. net/rev/delos/10/gcdr.pdf

DANE (2007). Colombia una nación multicultural: su diversidad étnica. Bogotá: Departamento Administrativo Nacional de Estadística.

DANE (2015). Chocó: pobreza monetaria 2014. Bogotá: DANE.

Escobar, A. (2004). Desplazamientos, desarrollo y modernidad en el Pacífico colombiano. En E. Restrepo y A. Rojas (Eds.), Conflicto e (in)visibilidad. Retos en los estudios de la gente negra en Colombia (pags. 53-72). Cali: Editorial Universidad del Cauca.

Escobar, A. (2010). Territorios de diferencia: lugar, movimientos, vida, redes. Popayán: Envión Editores.

Giménez, G. (2005). Territorio e identidad. Breve introducción a la geografía cultural. Trayectorias, VII(17), 8-24.

Galvis, L., Moyano L., y Alba, C. (2016). La persistencia de la pobreza en el Pacífico colombiano y sus factores asociados. Bogotá: Banco de la República. Recuperado de: http://www.banrep.gov.co/sites/default/files/ publicaciones/archivos/dtser_238.pdf

Giménez, G. (1996). Territorio y cultura. Estudios sobre las Culturas Contemporáneas, II(4), 9-30. Recuperado de http://www.redalyc.org/ pdf $/ 316 / 31600402$.pdf

Herrera, J. (2008). La reinvención de los derechos humanos. Andalucía: Atrapasueños.

Hoyos, C. (2015). Análisis de las causas del rezago en el desarrollo económico del departamento del Chocó. Santiago de Cali: Universidad ICESI. Recuperado de https://bibliotecadigital.icesi.edu.co/biblioteca_digital/bitstream/10906/78248/1/TG00945.pdf

Informe de Declaración de San José (1981). Sobre etnodesarrollo y etnocidio en América Latina. Recuperado de file:///C:/Users/juan\%20jose/ 
Desktop/03.\%20Declaración\%20de\%20San\%20José\%20sobre\%20etnodesarrollo\%20y\%20etnocidio.\%2011de\%20diciembre\%20de\%201981.pdf

IGAC (2002). Hidrografía del departamento del Chocó. Recuperado de https://geoportal.igac.gov.co/es/contenido/departamentales.

Las cifras que tienen indignado al departamento del Chocó (2016). Recuperado de http://www.eltiempo.com/colombia/otras-ciudades/las-cifras-que-tienen-indignado-al-choco/16678901

Lobo-Guerrero, A. (1993). Hidrología e hidrogeología de la Región Pacífica colombiana. En P. Leyva (Ed). Colombia-Pacífico (págs. 122-134). Bogotá: Fondo para la Protección del Medio Ambiente "José Celestino Mutis".

Mingorance, F., Minelli, F., y Le Du, H. (2004). El cultivo de la palma africana en el Chocó. Legalidad ambiental, territorial y derechos humanos. Recuperado de www.raulzelik.net/images/rztextarchiv/uniseminare/0411_ palma_africana.pdf

Moreno, F. (2011). Universalidad del buen vivir y economía por la vida. La vuelta al revés de las finanzas, la economía, la sociedad y los valores dominantes. HAOL, (26), 165-180.

Montañez, G., y Delgado, O. (1998). Espacio, territorio y región: conceptos básicos para un proyecto nacional. Cuadernos de Geografía, VII(12), 120-134.

Montoya, V. (2006). El mapa de lo invisible: silencios y gramática del poder en la cartografía. Universitas Humanística, (63), 155-179.

Nates, B. (2011). Soportes teóricos y etnográficos sobre conceptos de territorio. Co-herencia, 8(14), 209-229.

Organización de las Naciones Unidas (1986). Declaración sobre el Derecho al Desarrollo. Recuperado de https://cd3.uniandes.edu.co/sistema_derechos_humanos/sistemas_principales/sistema_universal/documentos/tratados/declaracion_sobre_el_derecho_al_desarrollo

Organización de las Naciones Unidas (2014). Restitución de tierras, un balance claroscuro en 2014. Bogotá: Oficina del Alto Comisionado. Recuperado de http://www.hchr.org.co/migracion/index.php/compilacion-de-noticias/93-tierras/5518-restitucion-de-tierras-un-balance-claroscuro-en-2014

Organización Nacional Indígena de Colombia (2010-2011). Palabra dulce, aire de vida. Bogotá: ONIC.

Pegoraro, J. (2013). El Control Social como custodio del orden social: selectividad e impunidad de los poderosos. C. Barreira et.al. (Coords). Conflictos sociales, luchas sociales y políticas de seguridad ciudadana (págs. 21-35). Toluca: Universidad Autónoma del Estado de México. 
Porto-Gonçalves, C. (2009). De saberes y de territorios - diversidad y emancipación a partir de la experiencia latinoamericana. Polis (22), 1-11. Recuperado de http://www.scielo.cl/pdf/polis/v8n22/art08.pdf

Proyecto Biopacífico. Informe General (1998a). Territorio biocultural. Tomo I. Bogotá: Ministerio del Medio Ambiente, GWEF-PNUD.

Proyecto Biopacífico. Informe General (1998b). Diversidad amenazada: prioridades de manejo y conservación. Tomo II. Bogotá: Ministerio del Medio Ambiente, GWEF-PNUD.

Proyecto Biopacífico. Informe General (1999). El Pacífico colombiano desde la perspectiva afrocolombiana e indígena. Tomo IX. Bogotá: Ministerio del Medio Ambiente, GWEF-PNUD.

Programa de las Naciones Unidas para el Desarrollo (2011). Colombia rural: razones para la esperanza. Bogotá: INDH y Programa de las Naciones Unidas para el Desarrollo.

Raffestin, C. (2011). Por una geografía del poder. Michoacán: El Colegio de Michoacán.

Reboratti, C. E. (2001). Una cuestión de escala: sociedad, ambiente, tiempo y territorio. Sociología, (5), 80-93.

Rodríguez, D., y Durán, O. J. (2014). Sos Chocó. Pacífico territorio de etnias. Revista de la coordinación regional del pacífico colombiano, (8), 3-6.

Roa, T., y Navas, L. M. (2014). Extractivismo. Conflictos y resistencias. Bogotá: Censat Agua Viva - Amigos de la Tierra Colombia.

Santacruz, M. (2006). Territorio y desarrollo: ¿Amores renovados? Revista de Economía \& Administración. Recuperado de http://www.uao. edu.co/sites/default/files/TERRITORIO_0.PD

Sosa, M. (2012). ¿Cómo entender el territorio? Guatemala: Cara Parens.

UNICEF (2003). Los pueblos indígenas en Colombia. Derechos, Políticas y Desafíos. Bogotá: UNICEF. Recuperado de https://www.unicef. org/colombia/pdf/pueblos-indigenas.pdf

Unidad de Restitución de Tierras (2014). Caracterización de afectaciones territoriales. Consejo Comunitario Mayor de la Organización Campesina del Alto Atrato (COCOMOPOCA). Recuperado de http://lamineriaenchoco.tierradigna.org/pdf/Caracterizacion_Cocomopoca.pdf

Verdadabierta (2014). Restitución de tierras, un balance claroscuro en 2014. Recuperado dehttps://verdadabierta.com/debates-de-la-restitucion-de-tierras-en-2014/ 
El eco-etnodesarrollo en el Chocó biogeográfico.

Estudio a partir del extractivismo y las luchas sociales por el territorio

Villa, W. (1998). Movimiento social de comunidades negras en el Pacífico colombiano. La construcción de una noción de territorio y región. Geografía Humana de Colombia, (6), 431-449.

Villa, W., y Houghton, J. (2004). Violencia política contra los pueblos indígenas en Colombia. 1974-2004, Bogotá: IWGIA. 